\title{
Introduction to the Digital and Cybernized Services Minitrack
}

\author{
Tilo Böhmann \\ Universität Hamburg \\ tilo.boehmann@uni-hamburg.de
}

\author{
Jan Marco Leimeister \\ University of St. Gallen \\ janmarco.leimeister@unisg.ch
}

\author{
Tuure Tuunanen \\ University of Jyväskylä \\ tuure@tuunanen.fi
}

The purpose of the minitrack is to attract research on the innovation, design, development, management, and use of digital services and the digitalization of services. The key drivers in this area of research are the multiplying technological opportunities for digital services, such as ubiquitous connectivity, artificial intelligence, wearable devices, cyber-physical systems, Internet of Things (IoT), virtual/augmented reality, and so on. The minitrack provides a discussion forum for researchers interested theoretical and practical problems related to such services [1-4].

In a broad sense, digital services can be defined as systems that enable value co-creation and limit value co-destruction through the development and implementation of ICT enabled processes that integrate system value propositions with customer value drivers [5-7]. Such services meld the worlds of bits and atoms and promise to transform the transportation, energy, and other sectors like the media industries before them. They draw on different technologies such as sensors, real-time analytics of data, augmented and virtual realities, computer hardware, software, and human and system actors. Such technologies form a service platform where different actors [] assemble the service together, in situ, as argued by Grönroos [9]. As a result, the embedded systems of today and the Internet-of-things of tomorrow are the precursors for the upcoming era of cybernized services [10]. Examples of such services are, e.g., biomedical and healthcare systems such as telerobotic surgery, (semi)autonomous vehicles and intelligent highways, augmented human capabilities with body net sensors and virtual reality, and intelligent machines.

Furthermore, there are substantial opportunities for ICT and digitalization driven service innovation in industrial and business-to-business settings. These opportunities exist particularly in manufacturing in which innovation activities increase the digitization of products and production processes. We see that the global awareness of the power of the manufacturing industry will be linked to horizontal cyberphysical systems that enable value co-creation and co-destruction in the networked business environment. The cyber-aspects of such systems are ICT infrastructure, computer hardware, software, and different kind of sensors and actors. These components turn cyber-physical systems into platforms for designing and operating service. The data on products and processes gained through networked cybernized services and the ability to act on this data through control systems and actors enables novel ways of cocreating service in industrial contexts.

This emerging area of research raises interesting questions [11]. For example, traditional development approaches focus on improving the efficiency and effectiveness of organizational processes. The design of such services may, however, require an emphasis on the sociopsychological aspects, such as the value-in-use and user/consumer/co-creator experiences. Digital services create novel ways of engaging customers and other actors in service ecosystems, raising the question of effective patterns of such digital actor engagement [5-8]. Moreover, digital services facilitate data-driven and analytics-based service design and development, particularly if the service is linked to the physical world through sensors and/or people's interactions. The shift of consumer and enterprise personnel from users to co-creators and co-destructors of value, calls for a significant re-appraisal of our current design and development approaches.

This year we received eight submissions, of which four were accepted to the minitrack with an acceptance rate of $50 \%$. This year all of the accepted papers dealt some aspects of digital service design. The articles are summarized in below.

Investigating Modular Reuse as an Underlying Mechanism of Conceptualization during Service Design - the Case of Key Activity Orchestration by Fabian Hunke, Hauke Thomsen, and Gerhard Satzger. The paper explores "modular reuse", a frequently used principle to efficiently implement and modify service processes in downstream as a possible underlying mechanism to inspire and facilitate the conceptualization phase. In a design science research approach, the authors develop and formatively evaluate three design principles, 
which enable the purposeful reuse of existing service elements for the conceptualization of new services.

Harnessing User Values to Understand Value CoCreation and Co-Destruction in Augmented Reality Mobile Games by Jenny Elo, Juuli Lintula, and Tuure Tuunanen. The paper explores the phenomena of value co-creation and codestruction in augmented reality mobile games. The study seeks to understand how users are active co-creators, co-destroyers, and determinants of value. The authors apply meansend theory to uncover key values highlighted in users' positive and negative gaming experiences through a qualitative content analysis of 43 indepth laddering interviews conducted with active Pokémon GO gamers in Finland. The paper demonstrates how user values may be operationalized to measure and understand value co- creation and co-destruction from service users' perspective, supporting value-based design and development of digital services.

Hybrid Service Recovery: Design for Seamless Inquiry Handovers between Conversational Agents and Human Service Agents by Mathis Poser, Sukhpreet Singh, and Eva Bittner. The paper proposes a hybrid service recovery strategy with real-time handovers of inquiries from conversational agents to human service agents, if conversational agents' capabilities are exceeded. Following a design science research approach, the authors present design principles for the inquiry handover scenario, based on meta-requirements derived from literature and expert interviews. Design principles instantiated as a prototype and evaluated for the suitability and interdependence of conversational agents' information collection activities and information presentation for handover.

Fostering Visibility, Commitment and Trust on Digital Platforms: Insights into Personal Engagement Platforms from the DACH Region by Lisa Lohrenz, Simon Michalke, Susanne RobraBissantz, and Christoph Lattemann. The authors conducted expert interviews with founders, CEOs, and managers of 14 personal and household-related service platform companies to gain insights into their activities and mechanisms for creating and maintaining successful engagement platforms. The paper offers a categorization according to the four categories: easing the entry, identifying mutual needs and problems, supporting co-creation, and facilitating service innovation. In addition, the data analysis found that the measures and activities carried out by platform owners are motivated by three concepts: trust, commitment and visibility.

\section{References}

[1] I. R. Bardhan, H. Demirkan, P. Kannan, R. J. Kauffman, and R. Sougstad, "An interdisciplinary perspective on IT services management and service science," Journal of Management Information Systems, vol. 26, no. 4, pp. 13-64, 2010.

[2] K. N. Lemon and M. H. Huang, "IT-Related Service: A Multidisciplinary Perspective," Journal of Service Research, vol. 14, no. 3, p. 251, 2011.

[3] R. F. Lusch and S. Nambisan, "Service Innovation: A Service-Dominant Logic Perspective," MIS Quarterly, vol. 39, no. 1, pp. 155-175, 2015.

[4] C. Peters et al., "Emerging digital frontiers for service innovation," Communications of the Association for Information Systems, vol. 39, no. 1, 2016.

[5] J. Lintula, T. Tuunanen, and M. Salo, "Conceptualizing the Value Co-Destruction Process for Service Systems: Literature Review and Synthesis," in Proceedings of the 50th Hawaii International Conference on System Sciences, 2017.

[6] T. Tuunanen, M. Myers, and H. Cassab, "A Conceptual Framework for Consumer Information Systems Development," Pacific Asia Journal of the Association for Information Systems, vol. 2, no. 1, pp. 47-66, 2010.

[7] T. Vartiainen and T. Tuunanen, "Value cocreation and co-destruction in an is artifact: Contradictions of geocaching," in $S$ Proceedings of 49th Hawaii International Conference on System Sciences, 2016.

[8] K. Storbacka, R. J. Brodie, T. Böhmann, P. P. Maglio, and S. Nenonen, "Actor engagement as a microfoundation for value co-creation," Journal of Business Research, vol. 69, no. 8, pp. 3008-3017, 2016.

[9] C. Grönroos, "Adopting a service logic for marketing," Marketing Theory, vol. 6, no. 3, pp. 317-333, 2006.

[10] T. Tuunanen, E. Kazan, M. Salo, R.-L. Leskelä, and S. Gupta, "From Digitalization to Cybernization," Scandinavian Journal of Information Systems, vol. 31, no. 2, p. 3, 2019.

[11] M. Barrett, E. Davidson, J. Prabhu, and S. L. Vargo, "Service Innovation in the Digital Age: Key Contributions and Future Directions," MIS Quarterly, vol. 39, no. 1, pp. 135-154, 2015. 